\title{
A Partial Gustafsson Bibliography
}

\section{POETRY}

Ballongfararna (1962); En förmiddag $i$ Sverige (1963); En resa till jordens medelpunkt och andra dikter (1966); Bröderna Wright uppsöker Kitty Hawk (1968); Kärleksförklaring till en sefardisk dam (1970); Varma rum och kalla (1972); Sonetter (1977).

\section{NOVELS}

Vägvila (1957); Poeten Brumbergs sista dagar och död (1959); Den egentliga berättelsen om herr Arenander (1966); Herr Gustafsson själv (1971); Yllet (1973); Familjefesten (1975); Sigismund (1976); En biodlares död (1978).

PLAYS

To̊̊ maktspel (1970).

ESSAYS

Utopier (1969); Konsten att segla med drakar (1969); Kommentarer (1972). Gustafsson is a leading critic for the Swedish daily, Expressen, and was the managing editor of the literary-cultural journal Bonniers Litterära Magasin from 1962-1972.

xxiii : Gustafsson Bibliography 
THIS PAGE INTENTIONALLY LEFT BLANK 